\title{
AGRICULTORES E INDUSTRIALES \\ EN EL NEGOCIO DEL PIMENTÓN, 1830-1935
}

\author{
JOSÉ MIGUEL MARTÍNEZ CARRIÓN \\ Universidad de Murcia
}

\section{RESUMEN}

Este artículo analiza los factores que determinaron la especialización regional del cultivo del pimiento y la competitividad de su producto industrial, el pimentón, en el mercado internacional. Se centra, por tanto, en las relaciones existentes entre agricultura $e$ industria alimentaria. Por el lado agrícola se destaca el papel de los propietarios y los productores en la difusión del cultivo en determinadas áreas de los regadíos del Segura y de la vega cacereña. Se señala que la expansión de la demanda favoreció la intensificación, provocó cambios significativos en la organización del trabajo campesino y facilitó la introducción del cambio técnico en las pequeñas explotaciones. Por el lado industrial, muestra la importancia del mercado nacional a finales del siglo Xxx y del comercio exterior a comienzos del siglo $\mathrm{xx}$, y se señala cómo los exportadores españoles se hicieron con el control del mercado mundial en la segunda década del siglo xx, en pugna con la paprika húngara. Se señala también cómo el papel de la organización industrial y de las empresas distribuidoras fue decisivo en la integración de los mercados, mejorando la calidad y la estandarización del producto. Se destaca, por último, cómo la difusión de técnicas de marketing, envasado en cajas y presentado con marcas, facilitó su aceptación y evitó la adulteración, constituyendo al final del periodo aspectos centrales de la comercialización del producto.

\section{ABSTRACT}

This paper analyses those factors that determined the regional specialization of pepper crop as well as the competitiveness of its industrial product, paprika, in international markets. Thus, it focuses on the relationship between agriculture and food industry. On the agriculture side, it is emphasised the role of cultivators on pepper diffusion in some irrigable areas of Segura river 
and Caceres valley. The demand expansion favoured crop intensification, provoked significative changes in peasant work organization, and facilitated technological advances in small farms too. On the industrial side, the present article shows the consumption importance in the national market at the end of nineteenth century and the foreign trade in the early twentieth century. In addition, it presents how Spanish exporters became to control the international market in the 1910's in conflict with Hungarian paprika. The role of industrial and commercial firms was decisive in paprika difussion in international markets enhancing its quality and standarization. Finally, the importance of marketing in the commercialization throughout 1920's and 1930's preventing paprika adulteration is reported.

\section{INTRODUCCIÓN}

Este trabajo analiza los factores que intervinieron en los procesos de especialización del pimiento para pimentón y de la competitividad del último en el mercado internacional entre mediados del siglo XIX y la década de 1930. Aunque está centrado en el análisis de un producto de escasa relevancia económica, si se compara con el volumen de las exportaciones de otros productos alimenticios españoles, pretende llamar la atención sobre algunas cuestiones que podrían ser de utilidad en el estudio del sector agroalimentario español antes de la Guerra Civil. Desea enfatizar asimismo las relaciones que se establecen entre agricultura e industria en los procesos de especialización e intensificación de los cultivos.

El artículo consta de cuatro partes. En la primera se señalan algunos de los factores que intervienen en los procesos de especialización de los cultivos mediterráneos y en la competitividad de los productos alimenticios sometidos a transformación industrial. La información disponible sobre la primera cuestión, aun siendo relevante en la literatura especializada, es todavía escasa en lo relativo a la segunda cuestión. Se argumenta la importancia de los factores medioambientales, institucionales, económicos y sociales en el desarrollo de la agricultura mediterránea y la dotación de ventajas comparativas en los mercados internacionales. La segunda parte se adentra en el estudio del cultivo y la producción del pimiento para pimentón, siendo las principales zonas productoras las comarcas de las vegas media y baja del Segura, en las provincias de Murcia y Alicante, respectivamente, y la comarca cacereña de La Vera. En esta parte se destaca el protagonismo que tuvo la pequeña explotación campesina en la difusión del cultivo desde mediados del siglo XIX, su importancia en los procesos de acumulación de capital en determinados sectores de campesinos arren- 
datarios de las vegas del Segura y se describen los procesos de trabajo asociados a las prácticas culturales intensivas requeridas en los plantíos en la principal área productora, la huerta de Murcia.

En la tercera parte se señala el papel de la industria pimentonera y la organización de los exportadores en la competitividad de los mercados mundiales. Por el lado de la demanda, destaca la importancia del mercado interior a lo largo de la segunda mitad del siglo XIX y del mercado exterior en el primer tercio del siglo $\mathrm{xx}$, y cómo los fabricantes españoles, mayoritariamente murcianos, consiguieron hacer frente a los exportadores magiares de paprika y arrebatarles el vasto mercado de los Estados Unidos durante la segunda década del siglo, consiguiendo desde entonces la primacía del mercado internacional. Por el lado de la oferta apunta cómo una mejora de la distribución y la organización del sector exportador contribuyó a la estandarización del producto, facilitando su aceptación en los mercados de consumo y evitando su adulteración en los centros de manipulación y comercialización. Por último, en la cuarta parte se exponen las conclusiones del trabajo.

\section{ESPECIALIZACIÓN Y COMPETTTIVIDAD DEL SECTOR ALIMENTARIO: ALGUNAS REFLEXIONES}

La expansión de la agricultura de regadío en las regiones mediterráneas y su competitividad internacional desde mediados del siglo $\mathrm{XIX}$ es uno de los aspectos mejor tratados en los últimos años por la historiografía agraria española ${ }^{1}$. La mayor parte de los estudios han abordado la cuestión señalando los efectos inducidos por los procesos de especialización e intensificación y reflexionando, en última instancia, sobre el papel desempeñado por la agricultura comercial y el sector agroalimentario en el desarrollo económico ${ }^{2}$. En uno y otro caso los análisis han primado la perspectiva regional, habida cuenta que tales procesos encuentran mejor documentación y apoyo empírico desde dicho enfoque.

${ }^{1}$ Desde que se publicara la obra colectiva de Historia agraria de la España contemporánea, coordinada por Ramón Garrabou, la literatura específica es demasiado amplia como para referirse a ella en esta ocasión. Recientemente, sobre la competitividad de la agricultura mediterránea pueden encontrarse visiones comparativas en Morilla Critz (1995, ed.) y Simpson (1997)

${ }^{2}$ Sobre el comercio exterior de productos agroalimentarios, Gallego y Pinilla (1996), Pinilla (1995b). 
El estudio de los diferentes procesos de especialización agraria ha reforzado, en primer lugar, el carácter dinámico y cambiante de la producción tanto agrícola como ganadera. La información disponible, sobre todo a escala local y regional, revela que una de las principales características de la agricultura mediterránea ha sido su adaptabilidad y versatilidad a las condiciones de los mercados. El grado de respuesta de los productores vino impuesto, en gran medida, por la presión de la demanda de productos alimenticios y hortofrutícolas en particular. En este sentido, los cambios que acontecieron como consecuencia de mejoras en el nivel de vida -aumento de la renta, nuevas pautas de consumo- hicieron posible que determinadas agriculturas reorientaran sus capacidades de producción y diseñaran estrategias tendentes a la mercantilización. La sustitución de cultivos tradicionales por cultivos de alto rendimiento comercial en las regiones mediterráneas con disponibilidades de riego es un hecho documentado desde mediados del siglo XIX ${ }^{3}$.

Uno de los factores en torno a la especialización, que sin duda requieren un tratamiento más riguroso en la historia agraria española, es el del consumo de los productos hortofrutícolas. La expansión de su consumo tuvo una serie de condicionantes desde mediados del siglo xIx: 1) el crecimiento de la población, ligado a un progresivo envejecimiento de la misma; 2) el aumento del poder adquisitivo en amplios sectores de la población como consecuencia del incremento de la renta; 3) las innovaciones tecnológicas que aumentaron la oferta de estos productos; 4) la mayor atención a las recomendaciones nutricionales, tras el papel desempeñado por los médicos «higienistas» y manifestado en la mejora de indicadores biomédicos, como el descenso de la mortalidad infantil y el aumento físico del tamaño de los cuerpos, en peso y en estatura, sobre todo desde finales del siglo XIX; 5) los cambios en la organización familiar —que afectaron al tamaño de los hogares y los núcleos conyugales- y en la esfera del trabajo; 6) el desarrollo de nuevas formas de comercialización y distribución, y, por último, 7) los cambios en los valores y hábitos culturales ${ }^{4}$.

La respuesta de los productores a la creciente demanda de los productos hortícolas y frutícolas estuvo también condicionada por el aprovechamiento de las ventajas comparativas asociadas a los recursos naturales y, en definitiva, la aclimatación de los cultivos. Además de la disponibilidad de recur-

${ }^{3}$ Sobre el papel de la demanda en la agricultura española del siglo xxx, Garrabou y Sanz Fernández (1985) y Simpson (1997).

4 Sobre la importancia de los cambios en las pautas de consumo alimenticio del campesinado y los niveles de vida, véase Martínez Carrión (1997). 
sos hídricos destacan otros condicionantes geofísicos, como la altitud, la insolación y la luminosidad en los procesos de especialización hortícola. El medio físico y las condiciones climáticas y edafológicas tienen un peso determinante en la dinámica de los cultivos y la calidad de su producción. Acorde con ello, las agriculturas mediterráneas desarrollaron varias lineas de especialización, y entre los «nuevos» cultivos de regadío destacaron - por su peso en la balanza comercial - los agrios - naranjas, principalmente-, las hortalizas - cebollas - y los frutales de hueso -melocotones, albaricoques y ciruelas- - El modelo de desarrollo agrario descrito quedó configurado en torno a los grandes valles y a varios ejes de expansión: las regiones que hoy integran el Arco Mediterráneo - Cataluña, País Valenciano y Murcia - y las del Valle del Ebro's.

El desarrollo de la especialización rebasaba el marco institucional del mercado y se adentraba en el mundo de las relaciones sociales. Se ha señalado que la vías de especialización se modificaban por las condiciones del mercado y que los procesos sustitutivos de unos cultivos por otros se veían, a menudo, acelerados por las variaciones de los precios y los beneficios. Aunque este planteamiento encuentra suficiente apoyo empírico, debe añadirse que el desarrollo exitoso de una vía de especialización no implicó que el campesino abandonara la producción de otros cultivos comerciales, y aún menos que desviara recursos destinados a la producción para el autoconsumo familiar. La pervivencia de cultivos tradicionales, como los cereales en las huertas mediterráneas en un régimen intensivo de rotación con hortalizas, demuestra que debe matizarse el papel de la especialización y analizarse en contextos sociales mediatizados por una multitud de factores ambientales, tecnológicos y económicos.

Especialización, diversificación y pluriactividad no eran incompatibles en el contexto de las pequeñas y medianas explotaciones campesinas. La marcada estacionalidad de los cultivos $\mathrm{y}$, sobre todo, la desigual distribución de la riqueza y la renta, como sugieren los estudios realizados sobre la estructura de la propiedad ${ }^{6}$, debieron forzar al campesino a adoptar estrategias tendentes al mantenimiento de cultivos para la autorreproducción familiar en combinación con cultivos especializados de naturaleza mercantil. Las estrategias fueron tan distintas como dispares los lugares donde se exploraron, a tenor de las relaciones sociales que se articularon con la implantación del capitalismo y en función de las disponibilidades tecno-

5 Sobre los procesos de especialización agrícola en las regiones señaladas, ver Gallego (1986), Garrabou (ed.) (1988), Martinez Carrión (1987), Pinilla (1995a) y Pujol (1988).

- Garrabou (1992, ed). 
lógicas, económicas y ecológicas. Información disponible sobre Cataluña, País Valenciano y Murcia revela la importancia que las relaciones sociales jugaron en el diseño de estrategias combinadas de especialización agraria ${ }^{7}$. Las huertas de Valencia y Murcia son acaso ejemplos muy característicos de lo que señalo. La existencia de unas rentas de situación favorables por la proximidad de los centros urbanos y una buena red de comunicaciones que enlazaba con el mercado nacional -en ambos casos, ferrocarril y comercio activo de cabotaje- debieron facilitar la temprana especialización en hortalizas y frutales.

El desarrollo exitoso de la especialización agraria no sólo dependía de las estrategias diseñadas por propietarios y campesinos. La existencia de redes comerciales y de compañías mercantiles que disponían de una tupida red de agentes distribuidores o de viajantes repartidos en distintos continentes, así como de fabricantes o industriales que ofertaban los productos de acuerdo con las modernas técnicas de marketing y diseño, son elementos a tener en cuenta en la interpretación de los hechos. Al fin y al cabo el objetivo de las compañías comerciales y de las empresas distribuidoras ha sido la conquista de clientela en nuevos mercados y mantenerla en caso de una fuerte concurrencia.

La mayor parte de la competitividad de los productos agroalimentarios venía dada más por el coste que por la calidad de la unidad. El precio final de un producto alimenticio manipulado dependía del coste de la tierra de cultivo, de los inputs - abono, agua, simientes, maquinaria-, y del empleo de mano de obra, y en menor medida del coste de manipulación del envasado o de la fabricación. Sin embargo, a partir de las primeras décadas del siglo $\mathrm{xx}$ se introducen nuevos elementos que confieren mayores dosis de calidad a los bienes alimenticios. Aunque es una hipótesis a confirmar es muy probable que determinados productos mediterráneos conquistaran los mercados internacionales no sólo incrementando la producción a granel, sino cuidando las formas de envasarla y presentarla con envoltorios exquisitos e, incluso, con refinadas etiquetas. A partir de entonces el dibujo, la estampación y el grabado de las marcas que identificaban a los productos constituían la carta de presentación de las casas comerciales en los escenarios internacionales. La concurrencia a ferias nacionales, certámenes internacionales y Exposiciones Universales y la consecución de premios o de algún tipo de valoración, suponían el reconocimiento a la

7 Garrabou, Pascual, Pujol y Saguer (1995) para Cataluna; Calatayud, Millán y Romero (1996) y Millán (1990) para el País Valenciano y Pérez Picazo, Martínez Carrión y Peréz Perceval (1996) para la región de Murcia. 
calidad del producto y la posibilidad de aspirar a conocer nuevos clientes y de entrar en otros mercados. El estudio sobre la participación de cosecheros y fabricantes del sector agroalimentario en estos certámenes revelaría la importancia que tuvo la mejora de la calidad en la competitividad internacional de los productos españoles.

En última instancia, los gustos de la demanda y la concurrencia internacional imponían - vía capital comercial o industrial - nuevas variedades en la gama de los productos agroalimentarios. De esta manera, los fabricantes o comerciantes entraban a forman parte en la toma de decisiones del proceso productivo, y en algunos casos hasta lo dirigían. Aún así, productores, cosecheros y fabricantes tenían comportamientos diferentes ante el mercado, alcanzando cotas de conflictividad en las negociaciones sobre la compraventa de materia prima para su distribución o manipulación industrial. A menudo aparecen enfrentados los grupos sociales en torno a la producción y los de la exportación, pero la información disponible se muestra poco concluyente. Existen indicios de que los exportadores y fabricantes mostraron tanto interés en preservar la calidad de la oferta manipulada y comercializada en los mercados como el de los cultivadores y propietarios por la del producto cultivado. En todos ellos la opción de reducir costes ante el incremento de la competitividad y la caida tendencial de los precios en los mercados internacionales fue determinante. Los conflictos vinieron, como se ha dicho, por el lado de la compraventa de fruta o productos alimenticios para su comercialización o industrialización. De ahí la importancia que cobran las interacciones y negociaciones que se producen entre los ámbitos de la producción agraria y los de la comercialización y la transformación de productos alimenticios.

El papel desempeñado por la organización de los agentes involucrados en los procesos de producción y comercialización pudo ser importante en las estrategias de especialización y mercantilización. A comienzos del siglo $\mathrm{xx}$ y, en concreto, a finales de la década de 1910 el protagonismo de los sindicatos agrícolas y las federaciones agrarias españolas puede considerarse como una respuesta organizada de los diferentes sectores a la creciente competitividad e integración de la agricultura en el mercado. La literatura sobre el asociacionismo y cooperativismo agrario resulta ya cuantiosa, y aunque es cierto que muchas de las instituciones que se crearon de manera gremial tuvieron un papel mediocre, fundamentalmente propagandístico, o bien actuaron como grupos de presión ante la política arancelaria y comercial, no debería menospreciarse su función de «mejoramiento de la producción agraria» que, en algunos casos, pudieron tener una par- 
ticipación destacada: financiando créditos y capital, organizando la producción, mejorando la distribución y prestando atención a la calidad de los productos para hacer frente a la competitividad ${ }^{8}$.

La capacidad de respuesta a la competitividad en los mercados internacionales venía dada, por lo general, de forma individual. Aunque las estrategias corporativistas y asociativas pudieron incidir en los progresos de la especialización y de la integración de la producción en los circuitos internacionales, la iniciativa empresarial individual fue determinante. Algunas empresas por sí mismas, al margen de las asociaciones gremiales, asumieron la importancia que la calidad del producto tenía en la distribución y en las decisiones de compra del consumidor, de ahí que redoblaran esfuerzos en incrementar su cuota de mercado mejorando la comercialización de los productos alimenticios. La proyección de una buena imagen a través de la difusión de firmas y marcas en los centros de consumo fue un objetivo central que debió imponerse en el comportamiento empresarial del sector agroalimentario. Pero en la comercialización de los productos agrarios, fueran o no manipulados industrialmente, fue importante la tendencia a la normalización y homogeneización del producto, sin perder de vista la tipicidad o diferenciación que un determinado producto alcanza sobre otros en relación con la calidad y su identificación con un territorio. Ésta se consiguió en los mercados a través de procesos de selección de semillas, utilización de materias primas autóctonas, introducción de variedades de alto rendimiento y de mejora de los controles de calidad. En España hay numerosos ejemplos entre los vinos (Jerez, Málaga, Montilla-Moriles...), las conservas vegetales (dulce de membrillo de Puente Genil...), aceite (Baena) o aceituna (la «sevillana»...), los productos ganaderos (jamón de Jabugo, las muchas denominaciones de quesos) o las frutas y hortalizas (fresas de Huelva, cerezas del valle del Jerte, uvas de Ohanes...), entre otros productos.

Estas observaciones previas acerca de los factores de la especialización y de las relaciones que entre agricultura intensiva e industria agroalimentaria se establecieron desde mediados del siglo XIX me permiten desarrollar algunos aspectos insuficientemente tratados en la historiografía: la competitividad de un producto debe valorarse no sólo dependiendo de la relación coste/beneficio inducida por el precio relativo de factores en el contexto de la explotación agraria, sino de la acción de una compleja combinación

${ }^{8}$ Sobre el cooperativismo agrario en la España del primer tercio del siglo xx ver Garrido Herrero (1996). Para Murcia, véase Martínez Soto (1997). 
de condicionantes que intervienen en las esferas de la producción y de la comercialización. El cultivo del pimiento pimentonero y su producto industrial, el pimentón, nos puede servir de test en el período comprendido entre las décadas de 1840 y 1930.

El cultivo del pimiento para pimentón ha tenido un desarrollo limitado geográficamente. Comenzó a expandirse en las primeras décadas del siglo XIX y encontró su mayor arraigo a comienzos del siglo XX en los regadíos murcianos y alicantinos, en la comarca cacereña de La Vera y durante un tiempo en la isla de Mallorca. Las vegas media y baja del Segura, concretamente una gran parte de las huertas de Murcia y de Orihuela, han sido históricamente las principales zonas productoras de pimentón dulce, frente a la variedad picante que se ha localizado tradicionalmente en la comarca cacereña. La documentación que presento, aun siendo básicamente murciana servirá para mostrar que la producción y la comercialización del pimentón entre 1860 y 1930 se asocian a diversos factores, entre los cuales destacaré: 1) la intensificación de la agricultura en el contexto de la pequeña explotación campesina; 2) la demanda de los mercados nacional e internacional a finales del siglo XIX; 3) las mejoras técnicas introducidas por los agricultores; 4) la organización de los fabricantes y exportadores, que tendieron a la normalización del producto y alcanzaron cotas de competitividad internacional en el primer tercio del siglo $\mathrm{Xx}$.

\section{ESPECIALIZACIÓN Y AGRICULTURA INTENSIVA: EL PAPEL DE LA PEQUEÑA EXPLOTACIÓN CAMPESINA}

\subsection{La difusión del cultivo y su importancia en la renta campesina}

La producción de pimiento para pimentón ha sido una de las principales fuentes de renta y de ingresos campesinos en las huertas de los ríos Segura y Guadalentín y, asimismo, de beneficios para los fabricantes y exportadores del sector. Llamado comúnmente «pimiento de bola» -obtenido de las especies Capsicum annum y Capsicum longum-, durante el siglo XIX y hasta mediados del siglo Xx se localizaba en las huertas de Murcia y de Orihuela (Alicante). Imperativos del mercado como consecuencia de enfermedades y cambios en el precio relativo de factores provocaron que, desde 1960, se trasladara su cultivo al valle del Guadalentín, campo de Cartagena y campo de Elche. Pese a ello, el proceso de molturación siguió estando hasta fechas recientes en manos de fabricantes y exportadores localizados 
en el municipio de Murcia y, particularmente, en las pedanías de Espinardo y Cabezo de Torres. Mientras que la comarca cacereña de La Vera se caracterizaba por el predominio de la variedad picante, la principal zona productora de pimentón dulce era la huerta de Murcia, que se convirtió en una de las principales zonas productoras del mundo durante las primeras décadas del siglo $\mathrm{xx}$, por encima, incluso, de las regiones húngaras productoras de paprika.

\section{CUADRO 1}

Superficie de pimiento para pimentón en España, 1910-1935

\begin{tabular}{|c|c|c|c|c|c|}
\hline$A \bar{n} o s$ & Murcia & Cáceres & Alicante & Baleares & España \\
\hline $1910 .$. & 2.699 & 2.173 & 500 & 180 & 5.552 \\
\hline 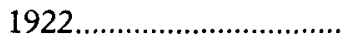 & 2.699 & 2.187 & 500 & 185 & 5.571 \\
\hline . & 3.115 & 1.370 & 3.118 & 65 & 7.668 \\
\hline 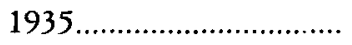 & 3.230 & 1.117 & 1.705 & 105 & 6.394 \\
\hline
\end{tabular}

FUENTE: A partir de los Anuario(s) Estadistico(s) de las Producciones Agrarias (en adelante, AEPA).

A diferencia de otros cultivos intensivos y de alto rendimiento comercial, que tuvieron mayor protagonismo a partir de la Primera Guerra Mundial, la especialización del cultivo del pimiento para pimentón es un hecho documentado antes de 1910. Los mayores progresos se habían realizado, tanto en Murcia como en Cáceres, durante la segunda mitad del siglo XIX, como sugieren los datos del cuadro 1. La escasez y precariedad de las estadísticas en este período nos impide seguir la tendencia con mayor precisión. La información que proporcionan las estadísticas agrarias españolas sobre el cultivo y la producción de pimiento pimentonero se da a conocer, precisamente, cuando las principales zonas productoras estaban ya consolidadas. Los primeros datos se facilitan en los Avances de la Junta Consultiva Agronómica, según las memorias de 1911 referidas a plantas hortícolas e industriales, publicados años más tarde por la Dirección General de Agricultura, Minas y Montes (Ministerio de Fomento, 1914). Pero lo más inquietante es el hecho de que los datos de Murcia -revelados por otras fuentes- ponen de manifiesto que la riqueza generada por el cultivo y la producción de pimentón en la primera década del siglo $\mathrm{xx}$ eran muy superiores a las cifras que señalaban las estadísticas oficiales. De ahí que tomemos con prudencia las valoraciones sobre las estadísticas nacionales, 
infravaloradas en los cultivos comerciales de alto rendimiento para los períodos anteriores a 1910. Obsérvese, además, que los datos de la superficie ocupada de 1910 se repiten en 1922, algo frecuente en otros cultivos. Hasta 1928, en que se publican los Anuarios Estadísticos de las Producciones Agrarias como consecuencia de la «reforma estadística» de 1927, no se regulariza la información anual.

La difusión del cultivo en los sistemas agrarios del regadio tradicional murciano tuvo que producirse en el primer tercio del siglo XIX. La información que proporcionan Miñano y Madoz revela la existencia de molinos dedicados exclusivamente para pimentón y la importancia de su comercialización hacia el mercado interior. El primero de ellos señala, por ejem. plo, que la mayor parte de las partidas se distribuían en las provincias de La Mancha y de Cuenca (Miñano, 1825: 402 y 405). Envasadas en sacos y presentadas en el mercado de San Julián de la ciudad de Murcia, que se celebrada tradicionalmente todos los jueves de cada semana, eran compradas por arrieros manchegos y andaluces para su distribución en el mercado castellano. Más tarde, Pascual Madoz (1845/9) sitúa el radio de acción comercial del producto en gran parte de la Península. Entre 1820 y 1850 se progresa en la conquista del mercado interior y el cabotaje desempeña, al parecer, un papel nada despreciable, como señalan las más de 300 toneladas anuales salidas por el puerto de Cartagena antes de la llegada del ferrocarril. Hacia 1840 el producto se oferta regularmente en los mercados de Quintanar de la Orden, Toledo, Tiedra (Valladolid) y Toro (Zamora), que abastecían, a su vez, a los arrieros del norte Cantábrico, pero sobre todo a los de Galicia, Asturias y norte de Portugal. Utilizado como condimento en guisos y embutidos, la expansión de la demanda fue extraordinaria a partir de la década de 1850 .

La conquista del mercado interior se refuerza con la llegada del ferrocarril y la mejora de las comunicaciones terrestres y marítimas. Los datos del cuadro 2, facilitados por un articulista de la prensa local en arrobas, muestran la tendencia claramente alcista en la segunda mitad del siglo XIX. Sorprende además la diferencia que existe entre los datos facilitados por esta fuente y las estimaciones de producción facilitadas por la Junta Consultiva Agronómica a partir de 1910 (cuadro 3). Los 92.000 Qm alcanzados en 1900, según la primera fuente, dejan en una situación de inferioridad los resultados cosechados en 1910 y 1922, estimados en poco más de 70.000 Qm. Aunque los primeros pecan posiblemente de optimismo, los segundos se descalifican por su repetición. Las fuentes de estimación hasta 1922 


\section{CUADRO 2}

Producción de pimentón en Murcia, siglo XIX

\begin{tabular}{|c|c|}
\hline Años & $Q m$. \\
\hline $1830 .$. & 3.450 \\
\hline $1850 \ldots \ldots \ldots \ldots \ldots$ & 5.750 \\
\hline $1860 \ldots \ldots \ldots \ldots \ldots$ & 17.350 \\
\hline $1870 \ldots \ldots \ldots \ldots$ & 34.500 \\
\hline $1880 \ldots \ldots \ldots \ldots$ & 46.000 \\
\hline $1890 \ldots \ldots \ldots \ldots$ & 69.000 \\
\hline $1900 \ldots \ldots \ldots \ldots \ldots$ & 92.000 \\
\hline
\end{tabular}

FUENTE: Elaboración a partir de El Liberal (7-4-1912).

son, como he señalado antes, bastante precarias por lo que deben tomarse como cifras aproximativas. Hasta 1928 no contamos con series relativamente fiables y homogéneas.

\section{CUADRO 3}

Producción de pimiento para pimentón en Murcia y España, 1910-1935 (en Qm.). Base 100 en 1910

\begin{tabular}{|c|c|c|c|c|c|}
\hline \multirow{3}{*}{ Años } & \multicolumn{2}{|c|}{ Producción } & \multicolumn{2}{|c|}{ Indices } & \multirow{2}{*}{$\frac{(\%)}{(1) /(2)}$} \\
\hline & Murcia & España & España & Murcia & \\
\hline & (1) & (2) & (3) & (4) & (5) \\
\hline 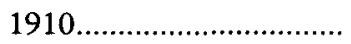 & 70.320 & 142.899 & 100 & 100 & 49,2 \\
\hline 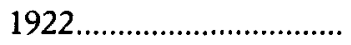 & 70.320 & 151.684 & 100 & 106 & 46,4 \\
\hline 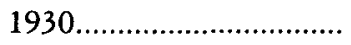 & 65.415 & 184.484 & 93 & 129 & 35,5 \\
\hline 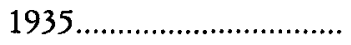 & 96.900 & 180.432 & 138 & 126 & 53,7 \\
\hline
\end{tabular}

FUENTE: $A E P A$.

El crecimiento de la demanda interior impulsó la expansión del cultivo del pimiento pimentonero en las décadas centrales del siglo xrx. La demanda externa cobró protagonismo a partir de 1870 , pero no fue significativa hasta la década de $1890 \mathrm{y}$, en el conjunto de las exportaciones españolas, hasta comienzos del siglo Xx. En cualquier caso, el impulso de la demanda había propiciado la especialización del cultivo y su arraigo en las pequeñas 
explotaciones campesinas de las huertas de las vegas media y baja del Segura: desde Alguazas y Molina hasta Orihuela. La difusión del cultivo había servido para incrementar la monetización en la economía campesina. En las huertas del Segura, al sur del País Valenciano, se documenta cómo en la década de 1840 los beneficios del producto se usan para pagar parte, al menos, de los salarios en las explotaciones de los grandes señores rentistas ${ }^{9}$. Los colonos usan la cosecha aún como garantía hipotecaria en el crédito agrario ${ }^{10}$. Esta modalidad de financiación entre los pequeños agricultores y arrendatarios pudo ser un recurso sistemático en la segunda mitad del siglo XIX que estimulara los procesos de intensificación de la agricultura comercial.

El papel del cultivo en los procesos de acumulación campesina debió de ser importante. Muchos propietarios estaban interesados en la difusión del cultivo para garantizarse así la renta ${ }^{11}$. Pero los pequeños cultivadores estaban tanto o más interesados que aquéllos por la posibilidad que la comercialización del producto les ofrecía para el ensanchamiento de los ingresos familiares. Así lo reflejan numerosos informes. El ingeniero Vicente Sanjuan, en 1887, señala que los colonos pagaban los arrendamientos de sus tierras con los beneficios de la cosecha y «les quedaban libres para atender a todas sus necesidades las demás cosechas que aquéllas -las vegas- producen» ${ }^{12}$. Los beneficios para cosecheros y fabricantes debieron ser importantes, lo cual se advierte no sólo por la expansión del cultivo, sino por la valoración que del mismo se realiza a comienzos de siglo xx. Otro ingeniero agrónomo, Zacarías Salazar, cifraba la riqueza generada en más de 15 millones de pesetas hacia 1900. Cantidad que es importante si tenemos en cuenta que la producción se reducía a menos de la mitad de la superficie de la huerta de Murcia y aun sabiendo que una estimación propia sobre el producto agrícola provincial en esa fecha es de 104 millones de pesetas ${ }^{13}$. La valoración de Salazar está muy por encima, además, de la que ofrecen, años más tarde, las estadísticas agrarias, pero en cualquier caso no deja de ser relevante.

El cultivo se encontraba bien arraigado en las pequeñas explotaciones campesinas de las vegas del Segura durante las últimas décadas del siglo XIX

${ }^{9}$ Calatayud, Millán y Romeo (1996), p. 99.

${ }^{10}$ Millán (1984), p. 106.

"Esto se recoge en los documentos del patrimonio del Conde de Ripalda, en la vega de Orihuela; ver Calatayud, Millán y Romeo (1996), p. 93.

${ }^{12}$ La crisis agricola y pecuaria, tomo V, (1887), p. 626.

${ }^{13}$ Salazar (1911), pp. 146-47. 
y encajaba dentro de un complejo sistema de rotación intensivo. El ciclo de alternancia con otros cultivos (cereales, plantas hortícolas y tubérculos) variaba extraordinariamente en la propia huerta, dependiendo de las variaciones de precios y la demanda, la disponibilidad de agua y otros factores $\mathrm{y}$, cómo no, de las exigencias del consumo doméstico. Su difusión a partir de 1840-1850 no implicó el abandono de determinados cultivos tradicionales que permitían alimentar al ganado y se destinaban, además, al consumo familiar. Pudo verse beneficiado, en cambio, por la crisis sericícola a causa de la enfermedad de las moreras a mediados del siglo XIX. Muchas de las plantaciones regulares tendieron a desaparecer como consecuencia de la pebrina y la caída de los precios sericícolas en el último tercio del siglo XIX. Los costes de oportunidad de la sustitución de una planta industrial por otra no albergaban dudas sobre la dirección encaminada por los agricultores. A diferencia de las moreras, el cultivo del pimentón permitía la intensificación y la alternancia con otros cultivos, manteniendo la producción sin interrupción a lo largo de todo el año. En este contexto, aumentó también la producción de la patatas, hortalizas y plantas forrajeras, destacando entre éstas la de alfalfa, que se destinaba a la explotación ganadera estabular. De esta manera los pequeños campesinos, fueran o no arrendatarios o colonos, mantenían un sistema de policultivo que tendía a incrementar la renta familiar campesina.

\subsection{Los procesos de trabajo: prácticas culturales y cambio técnico}

La producción de pimiento para pimentón tuvo que tener repercusiones sobre la organización del trabajo campesino, siendo un agente dinamizador del cambio técnico. Comenzando por el proceso de trabajo en las explotaciones agrícolas conviene señalar algunos aspectos significativos para la especialización. Estamos ante un cultivo muy exigente que empleaba cantidades importantes de factores. Las plantaciones requerían trabajo intensivo, labores esmeradas, abono y agua.

El proceso de trabajo comenzaba por la selección cuidadosa de semillas y la construcción de semilleros -almajaras, en Murcia; almácigas, en Cáceres-. En relación con el pimentón murciano, las variedades utilizadas eran más o menos homogéneas y concretadas en cuatro tipos: Albar, Ramillete, Tres Cascos y Bola. Por su escaso peso y su forma redondeada, se distinguía de los tipos de pimiento producidos en la Europa central y del este - Hun- 
gría, Bulgaria y Yugoslavia, principalmente- - en América -sobre todo, en California-, que eran de mayor peso, alargados y delgados ${ }^{14}$. Seleccionadas las variedades, el paso siguiente era la construcción de semilleros. En las vegas del Segura las almajaras formaban pequeñas parcelas - de 3 a 6 metros de largo por dos de ancho- excavadas en la tierra y resguardadas de los vientos del norte mediante la construcción de paredes inclinadas con cañizos y espartos o albardín de hasta tres metros de altura. Estos hoyos recibían grandes cantidades de abonos. Sobre la capa de estiércol, «muy becho y cernido», se efectuaba a voleo una siembra muy espesa de semilla, que se recubría de nuevo con estiércol y sobre la que se extendía una ligerísima capa de chinarro. Durante la noche, la superficie de los hoyos se recubría con albardín, a fin de favorecer la germinación, abrigar y estimular el crecimiento de las pequeñas plantas ${ }^{15}$. Esta esmerada preparación del terreno en los semilleros situaba el comienzo de las prácticas culturales intensivas que recibía el cultivo hasta su recolección.

La preparación del terreno para los plantíos se realizaba en los meses de enero a marzo y requería, al menos, cuatro labores, «de rejas cruzadas, tablamiento y trajillado del terreno», al objeto de dejarlo horizontal. Estas prácticas se hacían, normalmente, en los campos de cultivo del litoral cartagenero, en San Pedro del Pinatar, donde comenzó a difundirse a partir de la primera década del siglo Xx, gracias a los nuevos sistemas de captación de aguas subterráneas. Sin embargo, en las vegas del Segura la intensificación de los cultivos alcanzada en las parcelas hizo que las labores se sustituyeran por profundas cavas, seguidas de desterronamiento realizados con artefactos de madera ${ }^{16}$. De esa manera, la tierra conseguía una mayor transpiración y oxigenación. El trasplante de las plantas de los semilleros a los caballones se realizaba en los meses de abril o mayo, procediendo entonces al abonado y riego.

La recolección de las cosechas de pimientos variaba según se tratara para consumo en verde o para la fabricación de pimentón. Para el primero de los usos señalados se efectuaban dos recogidas del fruto antes de la recolección de pimiento para cáscara, en los meses de junio y julio. La recogida para cáscara con destino a la elaboración del pimentón tenía lugar en los últimos días de agosto y se prolongaba hasta noviembre, dependiendo del tiempo y el lugar, repitiéndose de tres a cuatro veces en la temporada.

${ }^{14}$ González Vidal (1986), p. 183.

is Salazar (1911), p. 175; Arroniz y Ordóñez (1931).

${ }^{16}$ Artículo sobre el tema en El Liberal (8 de septiembre de 1911); Arróniz y Ordóñez (1931). 
A finales de octubre se arrancaban las matas y se colgaban, si aún tenían frutos verdes, con la finalidad de que terminase su maduración, dando lugar a la cáscara de última calidad.

Las elevadas necesidades de riego y de abono, tanto en los semilleros como en los plantíos, desencadenaron tempranos procesos de mejora de los sistemas de captación y distribución de agua y aumentaron los rendimientos físicos. En relación con el riego, el consumo de agua por parcela en el pimiento/ón está estimado actualmente en 7.250 metros cúbicos por hectárea, siendo de los más fuertes junto al arroz, la alfalfa y el tomate ${ }^{17}$. $\mathrm{Su}$ alto consumo debió de generar numerosos conflictos en torno al agua, cuya gestión quedaba en manos de los heredamientos de las acequias y de la interpretación que de las ordenanzas hacía la Junta de Hacendados de la Huerta de Murcia. Pero abrió, sin duda, un potencial de mejoras tecnológicas que propiciaron el crecimiento de la productividad. Los procesos mecánicos de extracción se difundieron a finales del siglo XIX y se multiplicaron en las primeras décadas del siglo $\mathrm{xx}$ con la instalación de motores y artefactos que elevaban el agua movidos por gasolina, gas pobre y electricidad. El aprovechamiento de aguas subterráneas mediante pozos artesianos encontró su mayor desarrollo exitoso en los campos del litoral cartagenero, con 1.626 hectáreas de riego en $1916^{18}$. Por lo general, los agricultores de las huertas proporcionaban un riego cada seis o siete días en los semilleros y cada ocho días en las plantaciones. En el litoral cartagenero, donde las disponibilidades de agua eran menores, se regaban de ocho a quince días con aguas subálveas o artesianas. En cualquier caso, la relación simbiótica que se establecía entre la disponibilidad de agua, la intensidad del sol y la tierra otorgaba ventajas comparativas al territorio murciano y alicantino sobre el resto en la producción de pimentón dulce, y al de Cáceres en la variedad picante.

La difusión de guanos y abonos minerales tuvo lugar en el curso de la segunda mitad del siglo XIX, siguiendo una cronología similar a la establecida en el País Valenciano ${ }^{19}$. Sin embargo, las necesidades básicas de abono se cubrieron mayoritariamente con estiércol y nutrientes propios del sistema agrario, dada la relación simbiótica que la agricultura ejercía con la ganadería estabular y el entorno ambiental de las pequeñas explotaciones intensivas de huerta. A medida que aumentó el proceso de intensificación de los cultivos se multiplicó el consumo de abonos minerales,

${ }^{17}$ CES (1995), p. 242.

${ }^{18}$ La difusión de tecnología hidráulica en Martínez Carrión (1987), pp. 690-712.

19 Mateu y Calatayud (1994). 
dependiendo, sin embargo, del comportamiento de otros factores: precios relativos, centros de comercialización, experimentación y dificultades de adaptación.

Entre las prácticas tradicionales de abonado asociadas al ciclo vital agrario destacó el aprovechamiento que se hacía de las plantas del propio cultivo. Éste consistía en recoger, de manera cuidadosa, las matas de pimiento durante la época de arranque y fermentarlas con estiércol, empleándose dicho abono para la cosecha siguiente. Otras fórmulas «para enmendar la tierra» venían de utilizar mezclas de estiércol con tierra rica en sales de hierro procedente de terrenos especiales, práctica que al parecer era muy corriente en La Rioja ${ }^{20}$. El abonado comenzaba en los propios semilleros, practicándose cada dos o tres riegos en las almajaras. El consumo de estiércol osciló entre 67,5 y 125 toneladas por hectáreas, según diversas estimaciones, y dependió de la relación establecida con el consumo de otros abonos y fertilizantes minerales que comenzó a difundirse a finales del siglo XIX. El superfosfato de cal y el sulfato amónico se mezclaban con el estiércol y se espolvoreaban en la superficie de cada hoyo, según advierte Salazar (1911: 175). Para evitar que las plantas se dañaran por algún tipo de quemadura por la disolución depositada en ellas se limpiaban las hojas con regaderas. En las plantaciones, el abonado se efectuaba en dos tandas. La primera, al comienzo de mayo y antes del riego; la segunda, durante los meses de junio y julio.

- La lucha contra las plagas y el empleo de insecticidas constituye otro ejemplo de los progresos que acontecen en el sector con el fin de atenuar las fluctuaciones de la producción en los mercados y de eliminar las posibles pérdidas de beneficios. Entre las enfermedades que afectaban al cultivo del pimiento destacaban como recurrentes los pulgones y la roya. Las plagas del piojo y de la arroya eran frecuentes en el siglo XIX y en los años de sobreproducción se consideraban benignas por la elevación de precios que traían consigo ${ }^{21}$. Pero la respuesta del sector en la lucha contra las plagas dependía de medios técnicos, organización, ayuda estatal y experimentación. El papel del Estado en este sentido dejó mucho que desear, pues no se creó ningún organismo orientado a la mejora de la especialización agraria hasta fechas muy tardías, salvo la Estación Superior de Sericicultura en 1892. Incluso ésta, que estaba pensada como centro de experimentación agraria, no pudo abrirse hasta 1901 debido a la falta de medios técnicos.

\footnotetext{
${ }^{20}$ Hernanáez (1900), p. 92.

${ }^{21}$ El Diario de Murcia (29 de agosto de 1890).
} 
La iniciativa privada fue, por tanto, decisiva pero limitada por los condicionantes antes señalados ${ }^{22}$.

A principios del siglo $\mathrm{xx}$ mejora el conocimiento científico sobre las plagas y las formas de su erradicación. La difusión de ciertos medios técnicos en el campesinado encuentra apoyo por la organización del sector. Una de las plagas más frecuentes, como la de los pulgones, se combate con pulverizaciones de jugo de tabaco y empleando emulsiones jabonosas. Estos y otros insecticidas se aconsejan en los Boletines de la Cámara de Comercio que se difunden entre los agricultores acomodados durante la década de 1910. Los resultados debieron ser eficaces, como demuestran las reiteradas llamadas a estos procedimientos para luchar contra las plagas. La aplicación de conocimientos científicos y la experimentación química que se llevan a cabo en otros lugares aconsejan, en la década de 1920, el empleo de pulverizaciones de arseniato de plomo al 1 por 100. Los resultados conseguidos fueron excelentes, al igual que con el empleo de soluciones de jabón nicotinado y caldo bordelés ${ }^{23}$.

En definitiva, nos encontramos ante un cultivo que requería cuidados intensivos y esmerados, así como abundante mano de obra. La incorporación de prácticas culturales intensivas y la difusión de nuevas técnicas de abonado e irrigación debieron provocar cambios en la organización del trabajo campesino y mejoras de la productividad. No cabe duda que la difusión del pimiento para pimentón, como aquí se ha estudiado, y de otras plantas de huerta, como la patata, a lo largo del siglo XIX, hicieron posible una mayor eficiencia en el uso de factores. Los procesos de intensificación de los cultivos en los regadíos trajeron consigo mayores necesidades del factor trabajo, aminorándose con ello el desempleo relativo en determinadas estaciones del año. Si tenemos en cuenta que la emigración estacional contribuyó también a paliar el paro encubierto en la agricultura, fenómeno que se observa desde mediados del siglo XIX hacia Argelia, cobra sentido argüir como probable que mejorase la productividad del factor trabajo, es decir, que se produjera un aumento del producto agrario por trabajador ${ }^{24}$. Menos dudas ofrece, sin embargo, la argumentación de una mejora de la productividad del factor tierra. La intensificación de los cultivos de huerta y las mejoras técnicas tuvieron necesariamente que reper-

${ }^{22}$ El papel del Estado en este sentido fue irrelevante, ver Simpson (1997), pp. 158 y ss.

${ }^{23}$ Arróniz y Ordóñez (1931), p. 156.

24 Estas argumentaciones a escala nacional encuentran apoyo en Prados de la Escosura (1988). Una crítica de esta tesis se encuentra en Tortella (1994) y Simpson (1997). 
cutir en la mejora de la productividad de factor tierra, es decir, en el producto agrario por unidad de superficie. Ello explicaría el empequeñecimiento de las unidades de explotación que se ha observado entre 1820 y $1920^{25}$.

\section{MERCADO EXTERIOR Y COMPETITTVIDAD: EL PAPEL DE LA INDUSTRIA Y LA ORGANIZACIÓN DEL SECTOR EXPORTADOR}

\subsection{Las exportaciones y el mercado internacional}

Tras la conquista del mercado nacional a finales del siglo XIX, la búsqueda de nuevos mercados fuera de las fronteras fue el objetivo que se marcaron los exportadores y fabricantes de pimentón. La mejora de los sistemas de comunicación y de transporte marítimo fueron elementos que alentaron la expansión de la demanda. En realidad, las exportaciones a los mercados exteriores, en concreto hacia Argelia, Portugal y los mercados latinoamericanos, habían crecido en el curso de la segunda mitad del siglo XIX. Sin embargo, no comenzaron a ser relevantes hasta las décadas de 1890 y 1900 (cuadro 4).

La importancia de la oferta de pimentón murciano en el conjunto de las exportaciones españolas está fuera de duda, aunque los datos del comercio exterior de Cartagena sean poco relevantes. Hasta 1870, las partidas de cabotaje por el puerto de Cartagena superan con creces las del comercio exterior y suponen una parte importante de la producción murciana si comparamos los datos con los del cuadro 2. Desde 1890 cobran empuje las últimas, pero el cabotaje sigue ocupando un papel importante hasta la Primera Guerra Mundial. Aunque los datos del quinquenio de 1906-1910 son excepcionales, la participación comercial en su conjunto (cabotaje y exterior) se ha reducido en ese período. Cabe suponer que el ferrocarril cobró entonces un fuerte protagonismo. En principio, la mayor parte de la oferta se dirige al mercado interior, pero la importancia de negocio pimentonero en el comercio de exportación de los principales puertos españoles revela que una gran parte de la oferta murciana que salió por cabotaje y ferrocarril se reenvió al mercado exterior a través de dichos puertos. Algo similar pudo ocurrir con el pimentón cacereño, aunque en este caso

${ }^{25}$ Para la huerta de Murcia, Martínez Carrión (1988), Pérez Picazo, Martínez Carrión y Pérez de Perceval (1993). 


\section{CUADRO 4}

Destino de las exportaciones españolas de pimentón 1856-1920. Promedios anuales en Tms. Base 100 en 1876-1880

\begin{tabular}{|c|c|c|c|c|c|c|}
\hline \multirow{2}{*}{ Años } & \multicolumn{3}{|c|}{ Exportaciones } & \multicolumn{3}{|c|}{ Indices } \\
\hline & Europa & América & África & Europa & América & África \\
\hline $1856-1860 \ldots \ldots \ldots \ldots \ldots . . . . . . . .$. & 21 & 134 & 15 & 8 & 34 & 11 \\
\hline $1861-1865 \ldots \ldots \ldots \ldots \ldots \ldots$ & 22 & 175 & 44 & 8 & 44 & 33 \\
\hline $1866-1870 \ldots$ & 53 & 196 & 49 & 19 & 50 & 37 \\
\hline $1871-1875 \ldots \ldots \ldots \ldots \ldots \ldots$ & 183 & 332 & 73 & 66 & 84 & 54 \\
\hline $1876-1880 \ldots \ldots \ldots \ldots \ldots \ldots$ & 278 & 395 & 134 & 100 & 100 & 100 \\
\hline $1881-1885 \ldots \ldots \ldots \ldots \ldots . . . . . . .$. & 339 & 456 & 112 & 122 & 115 & 84 \\
\hline $1886-1890 \ldots \ldots \ldots \ldots \ldots$ & 497 & 558 & 196 & 179 & 141 & 146 \\
\hline 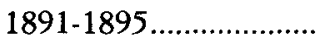 & 487 & 695 & 327 & 175 & 176 & 244 \\
\hline 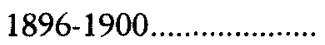 & 779 & 872 & 370 & 280 & 221 & 276 \\
\hline 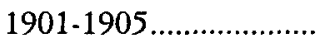 & 1.092 & 1.015 & 454 & 393 & 257 & 339 \\
\hline 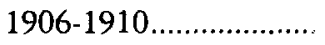 & 1.483 & 1.779 & 298 & 533 & 450 & 222 \\
\hline $1911-1915 \ldots \ldots \ldots \ldots \ldots . . . . . . .$. & 2.272 & 2.734 & 561 & 817 & 692 & 419 \\
\hline 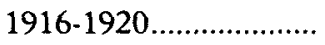 & 651 & 3.506 & 551 & 234 & 887 & 411 \\
\hline
\end{tabular}

Fuente: Estadística(s) de Comercio Exterior de España.

la información revela que la mayor parte se dirigía Portugal. Málaga, Alicante, Valencia, Barcelona y Bilbao eran los puertos de mayor actividad comercial relacionada con el negocio del pimentón. En conjunto, las exportaciones españolas suponen la tercera parte de la producción hacia la década de 1910.

Las exportaciones murcianas abastecían inicialmente a los mercados de demanda norteafricanos, mientras que los de Portugal se abastecían del pimentón cacereño de la comarca de La Vera. Los datos apuntan, no obstante, que la primacía de los mercados exteriores correspondía a la producción de Murcia, pero la endeblez de las estimaciones nos impide entrar en detalles por ahora. Hacia 1880 se ha calculado una producción de entre 1.100-1.400 toneladas de pimentón extremeño ${ }^{26}$ y de 4.600 toneladas aproximadamente de pimentón murciano. Esta última cifra no parece descabellada si se tiene en cuenta que en 1887 salieron por ferrocarril desde la Estación de Murcia 3.515 toneladas, a las que había que añadir «lo que se exportaba a lomo y en carro» ${ }^{27}$ que eran todavía medios de

\footnotetext{
26 Zapata (1986), p. 1221.

${ }^{27}$ El Diario de Murcia (21 de octubre de 1888).
} 


\section{CUADRO 5}

Las exportaciones españolas de pimentón y el comercio de cabotaje

y exterior de pimentón por Cartagena, 1861-1920

(Promedios anuales en Qm. Base 100 en 1876-1880)

\begin{tabular}{|c|c|c|c|c|c|c|}
\hline \multirow{3}{*}{ Años } & \multicolumn{2}{|c|}{ Comercio exterior } & \multicolumn{2}{|c|}{ Indices } & \multirow{2}{*}{$\frac{\text { Cabotaje }}{\text { Cartagena }}$} & \multirow{2}{*}{$\frac{\text { Indice }}{(5)}$} \\
\hline & España & Cartagena & España & Cartagena & & \\
\hline & (1) & (2) & (3) & (4) & (5) & (6) \\
\hline $1861-1865 \ldots \ldots$ & 2.405 & - & 30 & - & 3.579 & 134 \\
\hline $1866-1870 \ldots \ldots$ & 2.985 & - & 37 & - & 3.871 & 145 \\
\hline $1871-1875 \ldots \ldots$ & 5.877 & 49 & 73 & 14 & 3.871 & 145 \\
\hline $1876-1880 \ldots \ldots$ & 8.077 & 341 & 100 & 100 & 2.675 & 100 \\
\hline $1881-1885 \ldots \ldots$ & 9.117 & 333 & 113 & 97 & 2.225 & 83 \\
\hline $1886-1890 \ldots \ldots$ & 12.509 & 1.305 & 155 & 382 & 2.176 & 81 \\
\hline 1891-1895 ...... & 15.188 & 3.158 & 188 & 632 & 8.133 & 304 \\
\hline $1896-1900 \ldots \ldots$ & 20.403 & 3.049 & 252 & 893 & 9.521 & 356 \\
\hline $1901-1905 \ldots \ldots$ & 25.746 & 2.337 & 319 & 684 & 6.532 & 244 \\
\hline $1906-1910 \ldots \ldots$ & 35.911 & 1.910 & 444 & 559 & 32.573 & 1.218 \\
\hline $1911-1915 \ldots \ldots$ & 55.952 & 2.714 & 693 & 795 & 8.947 & 334 \\
\hline $1916-1920 \ldots \ldots$ & 47.229 & 3.717 & 585 & 1.088 & 2.377 & 89 \\
\hline
\end{tabular}

FuENTE: Estadistica(s) de Comercio Exterior de España y de Comercio de Cabotaje en España.

transporte importantes. Comparando estas cifras de Murcia con el volumen de las exportaciones españolas - entre 800 y 900 toneladas - se demuestra la importancia que tenía el mercado interior hasta finales del siglo XIX.

El fuerte crecimiento registrado por las exportaciones españolas de pimiento molido entre 1895 y 1915 (gráfico 1) estuvo protagonizado por la demanda europea y los tradicionales mercados latinoamericanos. Por parte de la oferta, las vegas del Segura cubrían la mayor parte de la misma (gráfico 2). Por parte de la demanda, Cuba y sobre todo Argentina (cuadro 7) constituían los principales centros de consumo en el continente americano, siendo la emigración gallega a dichos países la razón de la demanda, habida cuenta del alto consumo que el mercado gallego ejercía tradicionalmente en el mercado nacional desde mediados del siglo XTX. $\mathrm{Al}$ igual que hicieron los italianos con la pasta, los gallegos y en general los emigrantes de la España cantábrica realizaron una extraordinaria labor de difusión del producto dada la importancia que tenía en sus guisos y prácticas culinarias. En Europa, Portugal -que sobresalía por las reexportaciones desde allí hacia Brasil- y Francia pasaron a ser los países 
GRÁFICO I

Exportaciones de pimiento molido en España

1860-1935 (en miles de quintales métricos)

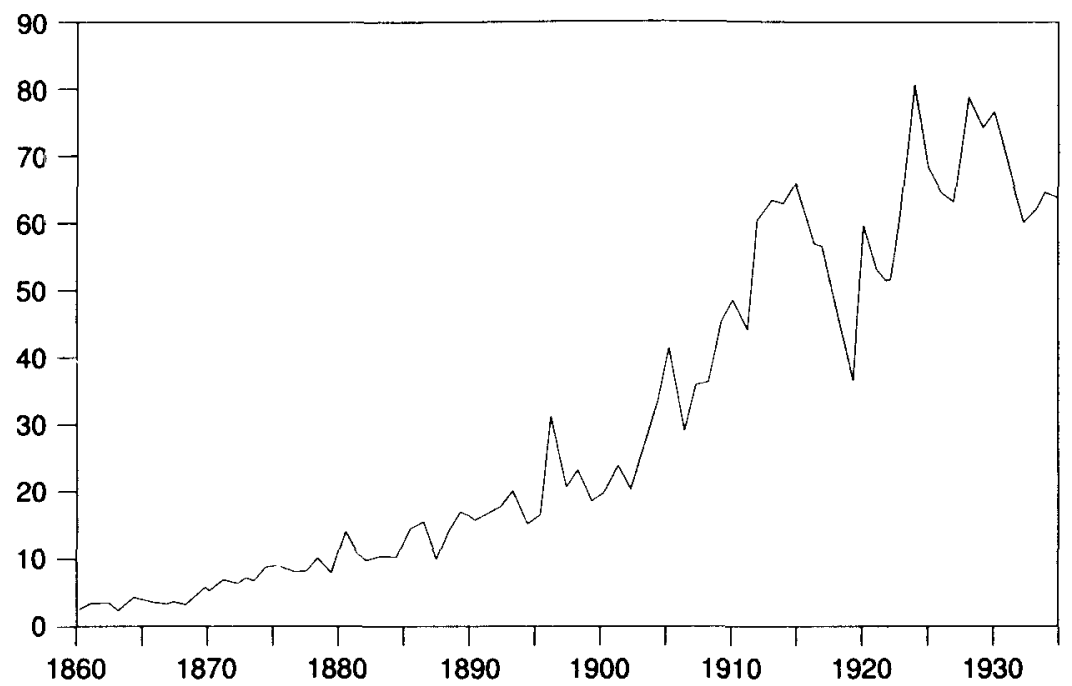

\section{GRÁFICO II}

Comercio de cabotaje y exterior de pimentón por el puerto de Cartagena, 1857-1921 (en miles de quintales métricos)

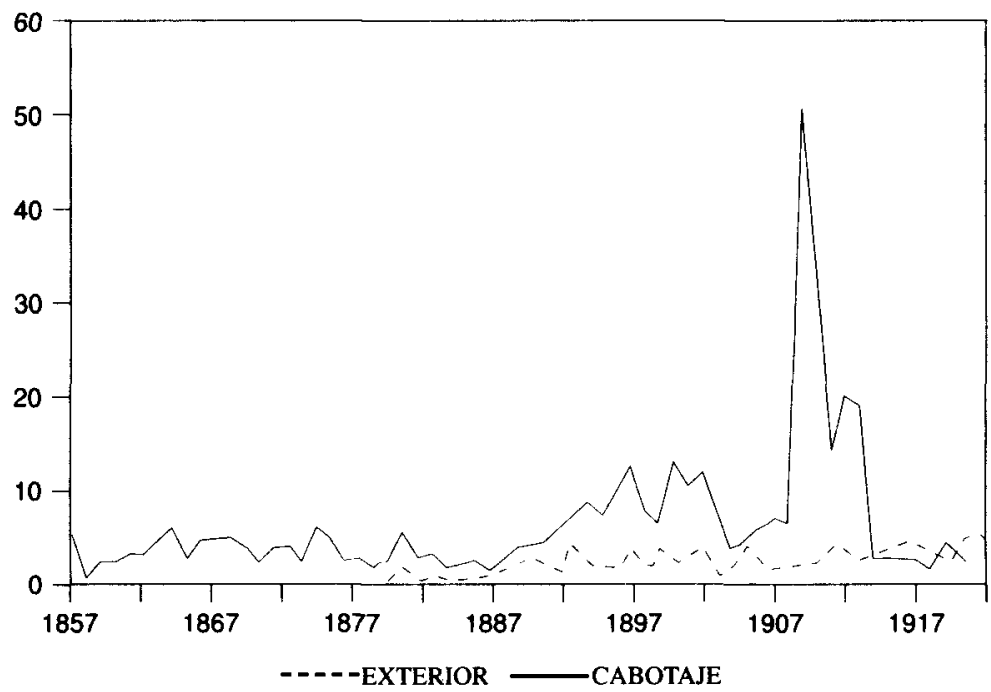


de demanda más importantes. Sin embargo, desde 1904 a 1914 el mercado austro-húngaro se muestra, repentinamente, como uno de los mejores clientes del pimentón español (cuadro 6).

$\mathrm{El}$ alto coste del pimentón húngaro y la dificultad de proveer a sus tradicionales mercados fueron las razones que impulsaron a los fabricantes magiares a la compra de pimentón español. Éste comenzó a rivalizar con la paprika hasta en sus propios mercados por la excelente relación precio/calidad. El hecho se explica porque el pimiento húngaro se cultivaba mayormente en zonas de secano, en concreto en las regiones de Szeged y Kalocsa, con menores disponibilidades de agua y fuerte irregularidad climática. La labor desempeñada por los fabricantes murcianos de pimentón en la penetración del mercado austro-húngaro fue notoria, como luego veremos. El creciente papel de este mercado hizo que las exportaciones europeas cobrasen tanta importancia como las americanas, alcanzando el 42 por 100 de las exportaciones españolas entre 1901-1910. Los fabricantes húngaros reexportaban buena parte de las importaciones españolas de pimentón al mercado de los Estados Unidos. Este, junto con Alemania, constituían los principales clientes exteriores de los pimentoneros magiares y el primero de ellos suponía un importante mercado potencial dado que su consumo crecía a pasos agigantados.

\section{CUADRO 6}

Exportación de pimentón español a Austria-Hungria, 1904-1914 (en Qm.) Porcentaje sobre las exportaciones españolas a Europa y el total

\begin{tabular}{|c|c|c|c|}
\hline \multirow{2}{*}{ Años } & \multirow{2}{*}{$\begin{array}{l}\text { Austria- } \\
\text { Hungria }\end{array}$} & \multicolumn{2}{|c|}{ Porcentaje } \\
\hline & & Europa & Total \\
\hline 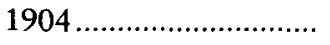 & 2.174 & 18,0 & 7,4 \\
\hline 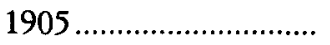 & 13.252 & 60,9 & 34,3 \\
\hline $1906 \ldots \ldots \ldots \ldots \ldots \ldots \ldots \ldots \ldots \ldots \ldots \ldots \ldots \ldots \ldots$ & 3.671 & 33,3 & 13,9 \\
\hline 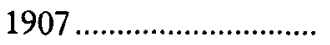 & 4.710 & 33,9 & 14,3 \\
\hline 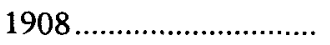 & 3.841 & 29,9 & 11,5 \\
\hline $1909 \ldots \ldots \ldots \ldots \ldots \ldots \ldots \ldots$ & 6.691 & 41,3 & 16,1 \\
\hline 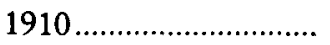 & 6.532 & 32,3 & 14,4 \\
\hline $1911 \ldots \ldots \ldots \ldots \ldots \ldots \ldots \ldots$ & 8.249 & 43,7 & 20,0 \\
\hline 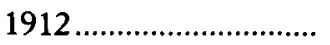 & 12.719 & 52,7 & 22,3 \\
\hline $1913 \ldots \ldots \ldots \ldots \ldots \ldots \ldots \ldots \ldots \ldots \ldots \ldots \ldots$ & 17.404 & 61,5 & 29,2 \\
\hline $1914 \ldots \ldots \ldots \ldots \ldots \ldots \ldots \ldots$ & 7.890 & 29,6 & 13,3 \\
\hline
\end{tabular}

FUENTE: Estadísticas de Comercio Exterior de España. 
La Primera Guerra Mundial supuso la primera gran crisis en el mercado internacional del pimentón y tuvo sus mayores efectos en el escenario europeo. El desmembramiento del imperio austro-húngaro provocó un serio revés a los pimentoneros húngaros, que vieron cómo se producía también el hundimiento de sus exportaciones. Las exportaciones españolas disminuyeron entre 1915 y 1919, resintiéndose sobre todo el mercado de la Europa central y del este. Sin embargo, tras la crisis la oferta española se reforzó en el mercado mundial. La contienda europea dio la oportunidad a los pimentoneros españoles y murcianos en particular de conquistar el vasto mercado de los Estados Unidos, hasta entonces en manos de los distribuidores húngaros. Fue una situación excepcionalmente favorable para el conjunto de los cosecheros y exportadores de pimiento molido español, como muestran las fuertes exportaciones registradas a partir de 1914 hacia dicho pais (cuadro 7).

\section{CUADRO 7}

Exportación españolas de pimentón a Argentina y Estados Unidos, 1891-1935. Promedios anuales en Qm. y porcentaje sobre el total de las exportaciones españolas

\begin{tabular}{|c|c|c|c|c|}
\hline \multirow{2}{*}{ Años } & \multirow{2}{*}{ Argentina } & \multirow{2}{*}{ EE.UU. } & \multicolumn{2}{|c|}{ Participación (\%) } \\
\hline & & & Argentina & EE.UU. \\
\hline $1891-1895 \ldots \ldots \ldots \ldots \ldots \ldots$ & 3.274 & 50 & 21,6 & 0,3 \\
\hline $1896-1900 \ldots \ldots \ldots \ldots \ldots$ & 3.571 & 63 & 17,5 & 0,3 \\
\hline $1901-1905 \ldots . . \ldots \ldots \ldots \ldots . . . . .$. & 5.113 & 228 & 19,8 & 0,9 \\
\hline 1906-1910.................... & 11.138 & 257 & 31,0 & 0,7 \\
\hline $1911-1915 \ldots \ldots \ldots \ldots \ldots \ldots$ & 14.175 & 4.068 & 25,3 & 7,3 \\
\hline $1916-1920 \ldots \ldots \ldots \ldots \ldots \ldots$ & 12.800 & 13.687 & 27,1 & 29,0 \\
\hline $1928-1930 \ldots \ldots \ldots \ldots \ldots$ & $15.257(a)$ & 24.938 & 21,2 & 34,6 \\
\hline $1931-1935 \ldots \ldots \ldots \ldots \ldots . . . . . .$. & $11.089(b)$ & 23.652 & 18,8 & 40,1 \\
\hline
\end{tabular}

(a) Sólo el año 1930 .

(b) Menos 1935.

FuENTE: Estadística(s) de Comercio Exterior de España y Cámara Oficial de Industria y Comercio, Murcia, núm. 55 (1934:7).

Pasados los efectos de la contienda europea, la recuperación de las exportaciones de pimentón húngaro se produce en la década de 1920, pero la composición del comercio exterior magiar se había modificado ligeramente. La mayor parte de las exportaciones se dirigen, fundamental- 


\section{CUADRO 8}

Exportación búngaras de pimentón.

Promedios anuales en Qm., 1909-1913 y 1927-1928

\begin{tabular}{|c|c|c|c|c|}
\hline & $1909-1913$ & $(\%)$ & $1927-1928$ & (\%) \\
\hline $\begin{array}{l}\text { Austria ......................... } \\
\text { Checoslovaquia............ }\end{array}$ & 4.189 & 57,2 & $\begin{array}{l}4.026 \\
2.445\end{array}$ & $\begin{array}{l}36,2 \\
22,0\end{array}$ \\
\hline Rumanía........................... & 244 & 3,4 & 2.576 & 23,1 \\
\hline Yugoslavia ....................... & 287 & 3,9 & 220 & 2,0 \\
\hline 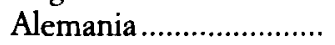 & 869 & 11,9 & 1.101 & 9,9 \\
\hline 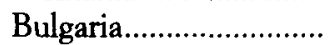 & 769 & 10,5 & - & - \\
\hline Estados Unidos ............ & 875 & 11,9 & 259 & 2,3 \\
\hline Otros países ...................... & 90 & 1,2 & 505 & 4,5 \\
\hline TOTALES ........... & 7.323 & 100 & 11.132 & 100 \\
\hline
\end{tabular}

FUENTE: Exportación, V, abril de 1934, núm. 70, pp. 8 y 13.

mente, hacia los antiguos territorios imperiales - Austria, Rumanía y Checoslovaquia- y Alemania (cuadro 8). A estas alturas, la competitividad del pimentón español en el mercado norteamericano impide a la paprika recuperar la cota alcanzada en 1909-1913. La penetración en dicho mercado fue extraordinariamente rápida. En 1916-1920 las exportaciones de pimentón a Estados Unidos representaban el 29 por 100 del total y en 1931-1935 suponían el 40 por 100 . La importante industria chacinera debió de ser el motor de la expansión de la demanda norteamericana. Las industrias de conservas, las queseras y la hostelería consumían grandes cantidades de este producto, que también encontraba gran aceptación en el consumo doméstico ${ }^{28}$. En pocos años, los Estados Unidos se habían convertido en el mejor cliente de la industria pimentonera española, posición que ha mantenido hasta la actualidad. Los datos de 1996 revelan que aunque el porcentaje ha disminuido, USA sigue ocupando el liderato en el consumo de pimentón español con una cuota del 16,8 por 100 .

La participación del pimentón murciano en las exportaciones españolas creció durante el primer tercio del siglo xx. La información revela que la mayor parte del comercio exterior español de pimentón al final del periodo descansa en la oferta murciana, hecho que se ha ido acentuando hasta la actualidad. El hecho cobra mayor dimensión cuando se sabe que la

\footnotetext{
${ }^{28}$ Exportación, V, núm. 70 (1934), p. 8.
} 


\section{CUADRO 9}

Exportación de pimentón español a Argelia, 1891-1920 y 1933-1934.

(Promedios en Qm. Base 100 en 1981-1895 y porcentaje sobre las exportaciones españolas)

\begin{tabular}{|c|c|c|c|}
\hline Años & Exportación & Indice & (\%) \\
\hline 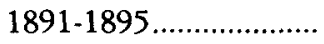 & 2.674 & 100 & 17,6 \\
\hline $1896-1900 \ldots \ldots \ldots \ldots \ldots$ & 2.347 & 125 & 16,4 \\
\hline $1901-1905 \ldots \ldots \ldots \ldots \ldots$ & 3.358 & 144 & 14,9 \\
\hline 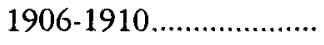 & 2.197 & 82 & 6,1 \\
\hline $1911-1915 \ldots \ldots \ldots \ldots \ldots \ldots$ & 2.833 & 106 & 5,1 \\
\hline 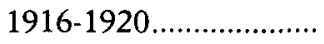 & 3.466 & 130 & 7,3 \\
\hline $1933.1934 \ldots \ldots \ldots \ldots \ldots$ & 6.614 & 247 & 11,2 \\
\hline
\end{tabular}

FUENTE: Estadística(s) de Comercio Exterior de España.

huerta de Murcia y las vegas del Segura constituían la principal zona productora. La variedad dulce y la calidad de su producto convertían al pimentón murciano en el eje de las exportaciones españolas. La participación del pimentón cacereño debió de disminuir en la tercera década del siglo $\mathrm{xx}$. Habiendo disfrutado de algunas ventajas - por las prohibiciones de la mezcla del producto con aceite en 1903 y la especificidad de su variedad picante, casi mayoritaria - comenzó a perder cuotas de mercado, como se desprende de la disminución de su cultivo. La producción de Cáceres que en 1906-1910 había sido del 35 por 100 en el total de la producción española, en 1929-1930 era sólo del 17,8 por $100^{29}$. Las ventajas comparativas del pimentón murciano quedaron sancionadas con la autorización oficial, en 1928, de la elaboración de pimentón mezclando adecuadamente el producto molido de la cáscara con aceite de oliva. Esta forma de elaboración del pimentón murciano daba al producto un color y paladar original y, por ello, gozaba de extraordinaria demanda en los mercados internacionales.

Los datos publicados por la Cámara Oficial de Comercio, Industria y Navegación de Murcia en 1942 revelan la importancia de las exportaciones murcianas que contrastan enormemente con las que facilita la Dirección General de Aduanas sobre el comercio exterior de pimentón español (cuadro 10). La diferencia entre ambas, en detrimento de las exportaciones españolas, es tan grande como sospechosa. La posibilidad de que las cifras

29 Zapata (1986), p. 338. 


\section{CUADRO 10}

Exportaciones de pimentón en España y Murcia, según diversas fuentes, 1908-1935.

Promedios en Qm. Base 100 en 1908-1910

\begin{tabular}{|c|c|c|c|c|c|}
\hline \multirow{2}{*}{ Años } & \multicolumn{2}{|c|}{ Exportación } & \multicolumn{2}{|c|}{ Indices } & \multirow{2}{*}{$\begin{array}{c}(A)-(B) \\
-\times 100 \\
(B)\end{array}$} \\
\hline & (A) & (B) & $(A)$ & (B) & \\
\hline $1908-1910$ & 40.111 & 62.722 & 100 & 100 & 63,95 \\
\hline $1911-1915 \ldots \ldots \ldots \ldots \ldots$ & 55.952 & 72.531 & 139 & 116 & 77,14 \\
\hline 1916-1920. & 47.229 & 64.676 & 118 & 103 & 73,02 \\
\hline $1921-1925 \ldots \ldots \ldots \ldots$ & 59.134 & 83.653 & 147 & 133 & 70,68 \\
\hline $1926-1930 \ldots \ldots \ldots \ldots \ldots$ & 67.145 & 79.706 & 167 & 127 & 84,24 \\
\hline $1931-1935 \ldots \ldots \ldots \ldots \ldots$ & 61.573 & 75.365 & 153 & 120 & 81,69 \\
\hline
\end{tabular}

FUENTE: (A) Comercio Exterior de España.

(B) Gremio de Exportadores de Pimiento Molido de Murcia, en Boletin de la Cámara de Comercio, Industria y Navegación de Murcia (1943:78).

de la COCIN incluyeran los flujos realizados por ferrocarril al mercado interior y que el gremio de los exportadores identificara comercialización con exportación es bastante certera. La comparación entre unos y otros resulta insatisfactoria y deben, por tanto, tomarse con mucha cautela los datos provenientes del gremio murciano. En cambio, existe mayor correspondencia entre los datos de «exportación» que facilitan los industriales y exportadores murcianos y los de producción que facilita los AEPA. A las cifras de los primeros podríamos otorgarles mayor confianza si computamos el volumen de comercialización total del producto fuera de la región.

En la década de 1920 las exportaciones de pimentón español habían alcanzado un techo histórico que no se rebasaría hasta la década de 1950. La oferta española casi monopolizaba el mercado mundial si se exceptúa la importancia de la paprika en los mercados de la Europa central y oriental. Incluso en éstos la presencia de la oferta española seguía siendo importante, pues en 1930 rebasaba el millar de toneladas ${ }^{30}$. El éxito comercial recaía en los menores costes de producción, como revela el comentario de una revista húngara: «este artículo - refiriéndose al pimentón español- ba acaparado todo el mercado mundial, por su precio baratísimo, con el cual el pimen-

\footnotetext{
${ }^{30}$ Flores Guillamón (1930).
} 
tón de Szeged no puede competir de ningún modo ${ }^{31}$. Disponibilidad de riego, costes salariales bajos por la importante participación del trabajo de la mujer, distribución y probablemente diferentes sistemas de manipulación son elementos a tener presentes para averiguar la ventaja comparativa del producto murciano y español.

Comprobar la competitividad exige, como es lógico, analizar las series de precios del producto en uno y otro país. Pero por ahora me ha sido difícil establecer una serie de precios del pimentón. La existencia de variedades y de clases diferentes de pimentón, dulce y picante, dificulta la tarea de reconstrucción de las cotizaciones, condicionada por la falta de información continuada ${ }^{32}$. Ante la falta de estos datos, sin embargo, sí que puedo proporcionar algunos otros, complementarios, acerca del proceso de elaboración y manipulación del producto que, de alguna manera, condicionaba los costes, y mostrar los progresos y las dificultades que tanto cosecheros como exportadores encontraron en la integración de los mercados internacionales.

\subsection{Organización empresarial y comercial en torno a la calidad del producto}

El proceso de elaboración del pimentón comenzaba con el proceso de desecación del producto nada más recogido el fruto. Los pimientos eran abiertos por las mismas cuadrillas — normalmente, formadas por mujeres- que efectuaban la recolección y, extendidos sobre cañizos, se colocaban al sol en las laderas de los montes próximos a las huertas o aprovechando cualquier prominencia que sirviera a tal fin. Los riesgos eran altos dado que la desecación se hacía en los meses de mayor peligro de lluvias y tormentas, durante los meses de septiembre a noviembre. Con este procedimiento el producto fresco perdía el 80 por 100 de su peso. Pero la imagen casi pintoresca de «manchas de grandes borrones de sangre» en las laderas y piedemontes de las cordilleras que rodeaban a la huerta desapareció por la mejora de las técnicas de desecación.

${ }^{31}$ Reproducido en González Marín (1944): 99.

${ }^{32}$ Un ejemplo de ello, en 1882 , el pimentón elaborado con cáscara extra se cotizaba a 20 pesetas la arroba, el de $2 .^{\mathrm{a}}$ clase entre 10 y 12 pesetas y las inferiores entre 6 y 9 pesetas. La cuestión se hace más compleja, pues existía otra cotización de pimentón mezclado con aceite. La ausencia de una Lonja en Murcia que aglutinara las actividades del mercado hizo que los precios variasen según el lugar de venta, fuese en Espinardo, donde se concentraba el grueso de la industria pimentonera, o en otros puntos de la huerta y de Murcia. 
Hasta finales del siglo XIX, si por efecto de las inclemencias del tiempo no se habían podido secar bien las cascarillas del pimiento, se llevaban a los alcabores de los hornos. Allí tomaban el punto seco y tostado que necesitaban para ser molidos. Sin embargo, a comienzos de siglo Xx se fueron imponiendo nuevos sistemas de secado artificial. Ello requería cierta capitalización. La respuesta del sector vino por la organización de los productores y los cosecheros. Los sindicatos agrícolas recién creados pusieron a disposición las estufas modelos Server y Berenguer que favorecieron el secado rápido y el ahorro de costes ${ }^{33}$, aunque tampoco faltaron los establecimientos comerciales que las distribuían. En la década de 1920, a petición del Gremio de Exportadores de Pimiento Molido, organización que agrupaba a los fabricantes y exportadores del sector, se realizaron ensayos en la Estación Sericícola, que puso a disposición los ahogaderos secantes. Se trataba de desecadores mecánicos y tenian la ventaja de que, a través de grandes ventiladores, llevaban corrientes de aire caliente a las cámaras donde se depositaba el producto y ello agilizaba la operación sin riesgo alguno. Pero el coste de estos procedimientos era elevado comparado con el de las estufas y, aun en esta época, se seguía recurriendo al sistema más tradicional de secado al sol.

Tras el proceso de secado se procedía al de selección del producto. Previamente se requería abrir los pimientos por el centro para quitarles los peciolos, tarea que realizaban las mujeres, y tras ello comenzaba la selección de los frutos en función de diversas calidades. Para quitarles las binzas o la simiente los percutían con palos de almendro o palmera, colocándolos en el suelo en forma de caballón. Esta tarea la desempeñaban los jornaleros. Inmediatamente las cáscaras pasaban a los molinos y a las fábricas para su molturación y elaboración. La molienda se realizaba en otoño, sobre todo en el mes de octubre, coincidiendo con las matanzas realizadas en las economías rurales, que tendieron entonces a consumir grandes cantidades del producto para los embutidos. El desarrollo de la industria chacinera y la mejora de los transportes fueron los factores que expandieron la demanda a comienzos de siglo $\mathrm{xX}$.

Los molinos de pimentón eran con frecuencia los mismos que elaboraban la harina, aunque el tamaño de las piedras era diferente. La exis-

${ }^{33}$ El nuevo sistema permitía madurar el producto sin prisas en las matas, aprovechar el buen tiempo de sol y con ello obtener ganancias en peso y calidad. El coste del nuevo sistema era menor al tradicional, pues «entre el acarreo, extenderlo, abrirlo, recogerlo y pérdidas de binzas sale a más de una peseta por arroba, mientras que la estufa sólo cuesta 75 céntimos»; ver artículo en El Liberal (19 de agosto de 1912). 
tencia de molinos exclusivamente para pimentón aumentó a partir de 1900, lo que sugiere una mayor especialización y capitalización del sector industrial. Las principales industrias harineras de la ciudad disponían de molinos y piedras especiales para la fabricación de pimentón. Entre 1923 y 1926 están documentados unos 200 molinos de tracción hidráulica, enclavados en su mayor parte en las acequias del Segura. Éstos daban movimiento a unas 480 piedras para la fabricación de pimentón, que entraban en funcionamiento durante la mayor parte del año. A ellos se sumaban unos 40 molinos movidos por electricidad ${ }^{34}$. El alto número de molinos pimentoneros y la fuerte concentración industrial del sector en el ámbito de la ciudad y la huerta de Murcia nos proporciona una idea de la contribución del sector al desarrollo económico de la comarca. La acumulación de beneficios generada en la esfera de la distribución debió de repercutir favorablemente en la mejora de equipamiento del sector y en la inversión hacia otros sectores.

La presencia de fraudes y adulteraciones que dañaban la calidad del producto fue uno de los mayores problemas con que tropezaron los cosecheros y, desde luego, los consumidores. En función de la demanda se empleaba mayor o menor cantidad de aceite, lo que se prestaba a numerosas adulteraciones. Éstas no sólo se realizaban con aceites industriales, sino que abarcaban un amplio abanico de posibilidades: harina de maíz, fucsina - materia colorante que se utiliza para los vinos-, polvo de cáscara de almendra y hasta serrín. El fraude alcanzó dimensiones extraordinarias en épocas de auge de la demanda y se prodigaba ante la falta de controles sobre la calidad del producto. Ni que decir tiene que ello incidía en la caída de los precios y ocasionaba serios trastornos - por desprestigioen los mercados, con la consecuente pérdida de beneficios empresariales. La adulteración estaba al alcance de todos y no escapararon a ella ni los grandes y más afamados cosecheros, como demuestran los numerosos informes y expedientes emitidos por el Ayuntamiento en algunos controles realizados en la estación ferroviaria ${ }^{35}$.

La organización del sector por controlar la calidad del producto y evitar las anomalías ocasionadas en el mercado por adulteración se produjo a finales del siglo XIX. La cuestión no era baladí, pues dependiendo de la modalidad de la adulteración los daños a la salud podrían ser considerables. Numerosas partidas quedaron precintadas por las autoridades municipales

\footnotetext{
${ }^{34}$ Cámara Oficial de Comercio e Industria de Murcia (1928), p. 11.

${ }^{35}$ Archivo Municipal de Murcia (AMM), Leg. 581. Años 1884-1885. Expedientes sobre adulteración de pimentón.
} 
por contener «sustancias nocivas» empleadas como condimento en la alimentación o los embutidos ${ }^{36}$. La adulteración también se realizaba en los centros de destino, como señalaron en numerosas ocasiones los industriales y exportadores de pimentón murciano. Las etapas de mayor intensidad en el fraude se advierten en la década de 1880 y a comienzos de siglo $\mathrm{XX}$, como revela el malestar ocasionado por la caída de las cotizaciones y el eco que de ello se hizo en la prensa local.

Las adulteraciones provocaron numerosos conflictos entre los productores de pimiento y los fabricantes de pimentón y trajo consigo la mejora organizativa del sector. La lucha por el control tuvo su mayor éxito con la creación de la Junta de Pimentoneros, en junio de 1884. Años más tarde, el 18 de marzo de 1888, se crea el Sindicato de Comerciantes de Pimiento Molido en la ciudad de Murcia. En respuesta a la organización de los fabricantes y exportadores de pimentón se crea en agosto de ese mismo año el Sindicato de Productores de Pimiento ${ }^{37}$, formado por 218 productores, propietarios y arrendatarios. Los conflictos se centran en la calidad del producto y la prohibición de la mezcla con aceite, que como se ha dicho propiciaba el fraude. La Real Orden del 4 de enero de 1887 desautorizó la elaboración de pimiento con aceite de oliva, aunque duró poco tiempo. Los controles se incrementaron en la estación ferroviaria de la capital, pero muchos exportadores los evadieron, remitiendo el producto por otras estaciones de la región: Alcantarilla, Archena, Lorquí y hasta desde Chinchilla ${ }^{38}$.

Cuando la demanda del mercado exterior se disparó, aumentaron de nuevo las adulteraciones. La situación se recrudeció entre 1900 y 1903. La lucha entre agricultores y distribuidores se centró de nuevo en la cuestión del aceite. Se daba por sentado que su utilización no era dañina para la salud, pero facilitaba la adulteración al ser un disolvente del color. En esta ocasión la batalla la ganaron los productores, con el apoyo de los grandes propietarios y de los grupos conservadores, mientras que los industriales recibieron el de los partidos liberales y demócratas. La fuerte campaña propagandística desatada en la prensa local y nacional hizo que intervinieran todo tipo de instituciones, desde el Director General de Sanidad, Ángel Pulido, hasta la Real Academia de Medicina. La Real Orden de 25 de agosto de 1903 y el Real Decreto de 31 de noviembre de 1903

${ }^{36}$ Destacó también el empleo de una sustancia denominada como «granos escarlatas»; El Diario de Murcia (27 de enero de 1884-30 de enero de 1884).

37 AMM, Leg. 953, doc. 44.

${ }^{38}$ El Diario de Murcia (26 de octubre de 1899). 
fijaban terminantemente la prohibición del uso de aceite de oliva en la elaboración del pimentón. Como había ocurrido a mediados de la década de 1880 , la situación alentó la mejora organizativa del sector. El 26 de diciembre de 1902 se aprueba el reglamento de la Sociedad de Exportadores de Pimiento Molido, que pasaría a denominarse con el tiempo Gremio de Exportadores. Por el lado de los cultivadores, en marzo de 1903 se crea la Unión de Productores de Pimentón, de vida efímera, a diferencia de los primeros, que se fortalecieron como grupo de presión a lo largo del primer tercio del siglo xx.

La competitividad en el mercado internacional pasaba por la mejora de la calidad del producto y ello exigía mayores controles. La competencia del pimentón cacereño en el mercado nacional y de la paprika en el mercado exterior era fuerte, aunque los éxitos acompañaban a los pimentoneros murcianos. En adelante, el papel del Gremio de Exportadores fue decisivo en la mejora de la calidad del producto ${ }^{39}$. En 1912 se solicita la exigencia del certificado de pureza en los envíos y la creación por el Ayuntamiento de un laboratorio químico especial para el análisis de dicho producto. No en vano los riesgos de perder el mercado austro-húngaro habían sido elevados por la continua presencia de irregularidades en las partidas enviadas, tal como se había denunciado en $1910^{40}$. La reacción del Gremio en ese año fue fulminante, nombrando dos inspectores encargados de evitar los fraudes ${ }^{41}$. La posibilidad del cierre de fronteras al producto murciano hizo que interviniera celosamente el embajador español en Viena. El resultado final fue favorable a los pimentoneros de Murcia, aunque la conflagración mundial, pocos años más tarde, desvaneció las posibilidades de expansión en el mercado imperial.

La imposición de certificados de pureza expedidos desde Murcia fue una exigencia de algunos mercados consumidores, a la que respondieron favorablemente algunos sectores de la exportación. El Gremio de Exportadores abanderó esta petición, que fue reiterada insistentemente desde comienzos de la década de 1920. Sin embargo, la falta de medios técnicos y la ausencia de apoyo institucional hizo que la cuestión siguiera en manos de la iniciativa particular, lo cual equivalía a la voluntad y buen criterio de los fabricantes y distribuidores. El papel del Estado en la mejora y el control de la calidad del producto fue muy tardío.

${ }^{39}$ El Liberal (29 de enero de 1912). AMM. Leg. 2092. Expediente de 24 de junio de 1912.

40 El Liberal (27 de febrero de 1910).

4) El Liberal (5 de julio de 1910). 
En la década de 1920 el pimentón español tropezaba con dos serios problemas: las adulteraciones, que posibilitaban los envíos a granel, y la caída de los precios por sobreproducción en los mercados internacionales. Ésta se había producido por la recuperación de la producción húngara y la puesta en cultivo de pimientos en nuevos territorios americanos y africanos (Argelia, Marruecos, Chile, California...). Ante esta situación, los exportadores españoles comenzaron a diseñar estrategias de marketing con la finalidad, primero, de consolidar los mercados americanos, y segundo, de aumentar cotas de competitividad. Como muchas de las adulteraciones se realizaban en los centros de destino, los exportadores comenzaron el abandono progresivo de los envíos a granel y a exportarlo en envases más pequeños, con sus respectivas marcas y etiquetas comerciales.

De esta manera se identificaba la calidad con las firmas comerciales y se conseguía la caracterización del producto. La normalización y la homogeneización eran condiciones necesarias para que el producto ofreciera garantías a los consumidores. Se trataba de estandarizar el producto de acuerdo con sus características de origen, en cuanto a sabor, aromas y color, e identificarlo con las marcas y envases diseñados como fórmula para evitar la adulteración y aumentar las posibilidades de venta. Para los exportadores, el factor fundamental que otorgaba la originalidad y tipicidad del pimentón dulce murciano era su color y aroma, además de su sabor. La exención de sabor picante y su coloración eran sus credenciales en los mercados. De tal manera, que su precio dependía de su contenido colorante, que lo debía, a su vez, a la variedad de los pimientos empleados y al procedimiento de elaboración.

La posibilidad de diferenciar el producto en los mercados de acuerdo con estas técnicas de marketing en la comercialización comenzó a difundirse entre los fabricantes y distribuidores. Estas estrategias -normalización y creación de marcas comerciales- venían realizándose desde finales del siglo XIX por algunas empresas productoras, aunque consiguieron imponerse a finales de la década de 1920 y comienzos de la de 1930. El ejemplo más significativo y pionero en la política de marcas comerciales lo encontramos en la empresa de Albarracín y Alemán, sociedad creada en 1880, que presentaba el producto con el nombre de «La Estrella». En 1908 era la principal empresa exportadora del país, y entre sus méritos destacaba que en 1900 había conseguido una medalla de oro a la calidad en la Exposición Universal de París ${ }^{42}$.

\footnotetext{
${ }^{42}$ El Liberal (8 de septiembre de 1908).
} 
El papel del Estado en la mejora de la calidad del cultivo y del producto vino tardíamente. Tras la insistente petición del Gremio de Exportadores, el Ministerio de Economía Nacional crea, en 1931, una sección técnica independiente, dentro de la Estación Sericícola de Murcia, que, en lo que atañe al cultivo del pimiento para pimentón se encargaría de estudiar la selección de semillas, la introducción de nuevas variedades y de procedimientos culturales, así como las alternativas más convenientes y mejorar la lucha contra las plagas. Asimismo, trataría de potenciar sistemas de secado y molido más eficaces, de presentación y envasado de la mercancía y luchar contra las adulteraciones y las falsificaciones ${ }^{43}$. Surgió de este modo, lo que más tarde se denominó Estación Pimentonera. Pero los resultados de este centro oficial dejaron mucho que desear debido a la endeblez de la dotación inicial presupuestaria. En 1934, la Estación aún no disponía de laboratorios para el análisis de tierras, cáscaras y pimentón, como denunciaba el propio Gremio de Exportadores ${ }^{44}$. De nuevo la falta de medios impidió modernizar tecnológicamente el sector y la respuesta dependió de la iniciativa particular, en este caso de los empresarios más arriesgados o del papel que llevó a cabo el Gremio en el control de la calidad.

A la altura de 1930 el mercado internacional comenzaba a mostrar síntomas de saturación y registraba un aumento de la concurrencia, como muestra la caída de los precios de exportación. No obstante, el mercado mundial seguía estando en manos de los pimentoneros españoles y murcianos en particular. De las 12.000 toneladas de pimentón que producía España, aproximadamente las $3 / 4$ partes se destinaban al mercado exterior. Pero la competitividad internacional de otros países había aumentado notablemente. Hungría había pasado de una producción de casi 3.000 toneladas, en 1928 a casi 5.000 toneladas en 1932. Otros países templados, como Chile, comenzaban a dejar su posición de consumidores de pimentón para acogerse a la de productores ${ }^{45}$. La situación internacional, por tanto, no era muy halagüeña para el sector, que debió ahora redoblar sus esfuerzos para combatir las adulteraciones que siguieron realizándose, sobre todo en los mercados norteafricano y sudamericano, y mejorar su competitividad.

${ }^{43}$ Industria y Comercio, XX, agosto de 1931, núm. 17, p. 12.

${ }^{44}$ Gremio Oficial de Exportadores de Pimiento Molido (1935), p. 15.

45 El Liberal (29 de julio de 1933). 


\section{CONCLUSIONES}

La expansión del cultivo de pimiento pimentonero y la fabricación de pimentón estuvieron asociados al papel creciente de la demanda del mercado nacional, primero, y mundial, después. El incremento de las exportaciones desde finales del siglo xIX y su competitividad hicieron posible el control del mercado internacional en la segunda década del siglo $\mathrm{xx}$, arrebatándole el protagonismo a la paprika o pimentón húngaro. El cultivo estuvo condicionado por el aprovechamiento de las ventajas comparativas asociadas a los recursos naturales y limitado a determinadas áreas del regadío del Segura y de la vega cacereña. La especialización del cultivo en la segunda mitad del siglo XIX provocó cambios significativos en la organización del trabajo campesino y facilitó la introducción del cambio técnico en el contexto de las condiciones ambientales y socioecómicas de las pequeñas explotaciones campesinas. En contra de lo que sostiene determinada literatura, la cuestión de la escala de las explotaciones agrícolas, dominada en este caso por pequeñas parcelas de tierra llevadas en régimen de arrendamiento, no frenó el desarrollo del cultivo ni obstaculizó la especialización agrícola. Por el contrario, los datos muestran que las pequeñas explotaciones campesinas respondieron adecuadamente a los estímulos de los mercados internacionales. La estructura de las explotaciones ni siquiera afectó a la productividad de la tierra, que aumentó a lo largo del período, y a los procesos de acumulación de capital, que hicieron posible el acceso de los colonos a la propiedad de la tierra a partir de la Primera Guerra Mundial.

El papel de la organización industrial y de las empresas distribuidoras fue determinante en la integración de los mercados, mejorando la calidad y la estandarización del producto. A diferencia de otros sectores productivos, la temprana constitución de asociaciones gremiales y representativas de los fabricantes y exportadores de pimentón facilitó las negociaciones con las instituciones y permitió conseguir información sobre los mercados que de otra manera se hubiera visto restringida a unas pocas empresas. El papel del Estado fue, sin embargo, escaso y tardío, pues muchas de las peticiones que se realizaron por el sector con el fin de mejorar la calidad del producto y que iban dirigidas a la investigación y experimentación tecnológica no llegaron a buen término. El caso más significativo fue la Estación Pimentonera. De ese modo, el cambio técnico y la mejora de la calidad quedaron en manos de la iniciativa empresarial. La difusión de técnicas de marketing, en donde adquiere importancia la presentación del producto 
y el envasado con marcas, facilitó su aceptación y evitó la posibilidad de la adulteración. Desde finales del siglo XIX los canales de comercialización toman protagonismo no sólo en cuanto al volumen, sino en las formas, pero aún constituyen aspectos testimoniales en algunas empresas o firmas comerciales. A la altura de 1930 la imagen del producto y el embalaje dejan de ser marginales para convertirse en aspectos centrales de la comercialización.

\section{AGRADECIMIENTOS}

Una versión preliminar de este artículo fue presentada en el VI Congreso de Historia Económica, celebrado en Girona (15-17 de septiembre de 1997), a la sesión especializada de «El contexto internacional de la agricultura española (1850-1990)». El autor agradece los comentarios del relator de dicha sesión, José Morilla, así como los que posteriormente ha recibido de Ramón Garrabou, Jesús Millán, Vicente Pinilla, Sergio Román, Santiago Zapata y de dos evaluadores anónimos de la Revista. Los fallos son responsabilidad exclusiva del autor. El trabajo se ha realizado dentro de los proyectos PB91-0947, financiado por la DGICYT, y HUM 96/16, financiado por la Dirección General de Universidad de la Consejería de Educación y Cultura de la Comunidad Autónoma de Murcia.

\section{REFERENCIAS BIBLIOGRÁFICAS}

Arróniz SalA, C., y Ordónez, E. (1931): «El cultivo del pimiento y la fabricación del pimentón en la región murciana», Agricultura. Revista agropecuaria, III, 27, pp. 153-157.

Calatayud, S., y Mateu, E. (1995): «Tecnología y conocimientos prácticos en la agricultura valenciana (1840-1914)», Noticiario de Historia Agraria, V, 9, pp. 43-67.

Calatayud, S.; Millán, J., y Romeo, M. ${ }^{a}$ C. (1992): «Les transformacions de la societat agrària en el procés de desenvolupament capitalista: el regadiu valencià el segle XIX», Recerques, 25, pp. 125-138.

Calatayud, S.; Millan, J., y Cruz, M. ${ }^{\text {a }}$ (1996): «La noblesa propietària en la societat valenciana del segle XIX: el comte de Ripalda i la gestió del seu patrimoni», Recerques, 33, pp.

Cámara Oficial de Comercio e Industria de Murcia (1928): Memoria de los trabajos realizados por la misma en los años de 1923 a 1926, ambos inclusive, Murcia, Tip. Nogués. 
CONSEjO ECONÓMICO Y SOCJAL (1995): Recursos bidricos y su importancia en el desarrrollo de la Región de Murcia, Murcia, CES.

Flores Guillamón, J. (1930): «Lo que el Gremio de Exportadores de Pimentón ha hecho y aún puede hacer por la industria pimentonera», Industria y Comercio, XVIII, 9, pp. 13-17.

Gallego Martinez, D. (1986): La producción agraria de Álava, Navarra y La Rioja desde mediados del siglo XIX a 1935, Madrid, Universidad Complutense.

GALLEGo MARTÍNEZ, D. (1998): «De la sociedad rural en la España contemporánea y del concepto de sociedad capitalista: un ensayo», Historia Agraria, 16, pp. 13-53.

Gallego Martínez, D., y Pinilla Navarro, V. (1996): «Del librecambio matizado al proteccionismo selectivo. El comercio exterior de productos agrarios y alimentos en España entre 1849 y 1935», Revista de Historia Económica, XIV, 2, pp. 371-420.

GARRABOU, R. (1988, ed.): La crisis agraria de fines del siglo XIX, Barcelona, Crítica.

- (1992, ed.): Propiedad y explotación campesina en la España contemporánea, Madrid, MAPA.

Garrabou, R, y SANZ Fernández, J. (1985): «La agricultura española durante el siglo XIX: ¿inmovilismo o cambio?», en GARRABOU y SANZ FERNÁNDEZ (eds.), Historia agraria de la España contemporánea. 2. Expansión y crisis (1850-1900), Barcelona, Crítica, pp. 7-191.

Garrabou, R.; Pascual, P.; Pujol, J., y Saguer, E. (1995): «Potencialidad productiva y rendimientos cerealícolas en la agricultura catalana contemporánea (1820-1935)», Noticiario de Historia Agraria, 10, pp. 89-130.

GARRIDO, S. (1996): Treballar en comú. El cooperativisme agrari a Espanya (1900-1936), Valencia, Alfons el Magnànim.

GONZÁlEZ MARÍN, F. (1944): Industrias murcianas derivadas de la agricultura, Murcia, Imprenta Provincial.

Gonzallez VIDAL, J. M. (1986): «El pimentón, industria murciana», La Cámara de Comercio. Historia viva de Murcia, 1899-1986, Murcia, Cámara Oficial de Comercio, Industria y Navegación de Murcia, pp. 181-192.

Gremio Oficial de Exportadores de Pimiento Molido de Murcia (1935): Memoria de 1934, Murcia.

Hernansáez, J. M. (1900): Notas sobre el tema Estado actual de la Agricultura en la Huerta de Murcia y Progresos de que es susceptible, Murcia, Imprenta Heraldo de Murcia.

MARTINEZ CARRIón, J. M. (1987): Desarrollo agrario y crecimiento económico en la región de Murcia, 1875-1935, Murcia, Universidad de Murcia (1990, en microfichas).

- (1988): «Peasant household formation and the organization of the rural labor in the valley of Segura during the ninenteenth century», Joumal of Family History, 13,1, pp. 91-109.

- (1997): «Los niveles de vida del campesinado en la España contemporánea. Algunas reflexiones», Noticiario de Historia Agraria, 14, pp. 25-57.

Martinez Soto, Ángel P. (1997): «Las vías de financiación de la agricultura murciana entre 1870-1936: el problema del crédito agrícola», Agricultura y Sociedad, 84 , pp. $49-106$. 
Millán, J. (1990): «L'economia i la societat valencianes, 1830-1914. Les transformacions d'un capitalisme perfèric», en Ruiz Torres (coord.), Història del País Valencià, vol. V, Época contemporànea, Barcelona, 62, pp. 26-76.

- (1984): «Antiliberalisme, protesta i subordinació popular al sud del País valencià. El tradicionalisme polític en el desenvolupament d'una agricultura intensiva», Recerques, 16 , pp. 95-118.

Ministerio de Fomento. Dirección General de Agricultura, Minas y Montes (1914): Avance estadistico de la riqueza que en España representa la producción media anual de las plantas bortícolas y plantas industriales. Resumen becho por la Junta Consultiva Agronómica de las Memorias de 1911, remitidas por los Ingenieros del Servicio Agronómico Provincial, Madrid.

Morilla CRITZ, J. (1995, ed.): Califormia y el Mediterráneo. Estudios de la bistoria de dos agriculturas competidoras, Madrid, MAPA.

Pérez Picazo, M. T.; Martínez Carrión, J. M.; Pérez de Perceval, M. A. (1993): «Estructura de la explotación y cambio agrario en los regadíos murcianos (1820-1920)», Áreas. 15, pp. 113-136.

- (1996): Grupos sociales, estructura productiva y explotación agraria en el sureste español en los siglos XIX y XX, Memoria del Proyecto de Investigación PB91-0947 de la DGICYT.

PINILlA, V. (1995a): Entre la inercia y el cambio. El sector agrario aragonés, 1850-1935, Madrid, MAPA.

- (1995b): «Cambio agrario y comercio exterior en la España contemporánea», Agricultura y Sociedad, 75, pp. 153-180.

PujoL, J. (1988): Les transformacions del sector agrari catala entre la crisi finisecular i la Guerra Civil, Barcelona, Universidad Autónoma de Barcelona.

Prados de la Escosura, L. (1988): De imperio a nación. Crecimiento y atraso económico en España (1780-1930), Madrid, Alianza.

SALAZAR, Z. (1911): La agricultura en la provincia de Murcia, Madrid, Im. Jaime Ratés.

SimpSON, J. (1997): La agricultura española (1765-1965): la larga siesta, Madrid, Alianza.

TORTElla, G. (1994): El desarrollo de la España contemporánea. Historia económica de los siglos XIX y XX, Madrid, Alianza.

ZaPATA, S. (1986): La producción agraria de Extremadura y Andalucía occidental, 1875-1935, Madrid, Universidad Complutense. 